\title{
TIBF TESTING THE PERFORMANCE OF ASSET PRICING MODELS IN DIFFERENT ECONOMIC AND INTEREST RATE REGIMES USING INDIVIDUAL STOCK RETURNS
}

\author{
Ann Marie Hibbert and Edward R. Lawrence \\ West Virginia University Morgantown and Florida \\ International University, United States
}

\begin{abstract}
Using return data for all stocks continuously traded on the NYSE over the period July 1963 to December 2006, we tested the performance of the two-moment Capital Asset Pricing Model (CAPM) and the Fama French three-factor model in explaining individual stock returns. We found the performance of Fama French three-factor model to be marginally better than the CAPM. We further test the models for the significance and stability of parameters in the bull/bear periods and the Federal increasing/decreasing interest rate periods and found the performance of the two models comparable.
\end{abstract}

Keywords: CAPM, Three-factor model, Asset pricing, Bear-bull periods, Interest rate regimes

JEL category: G12, G30.

\section{Introduction}

Sharpe's two-moment capital asset pricing model is the model most widely used to obtain the discount rate (required rate of return or the cost of equity capital). Graham and Harvey (2001) survey a sample of 392 firms and find that "CAPM is by far the most popular method of estimating the cost of equity capital: $73.5 \%$ of respondents always or almost always use the CAPM". Even though practitioners use asset pricing models to predict the required return on individual assets, most researchers have used returns on portfolios to test different asset pricing models. ${ }^{1}$

${ }^{1}$ The formation of portfolios in asset pricing tests was introduced initially by researchers such as Blume (1970), Friend and Blume (1970) and Black, Jensen and Scholes (1972) and further enhanced by Fama and MacBeth (1973) to improve the precision of estimated betas for use in cross-sectional regression analysis. 
Using portfolio returns, researchers find the performance of CAPM less promising as compared to its most prominent rival, the Fama French three-factor model. In this paper we use individual stock returns data to test the performance of CAPM and the Fama French three-factor model and found that contrary to the highly superior performance of Fama French three factor model using portfolio returns data, when tested on individual stock return data, the Fama French threefactor model performs marginally better in explaining the stock returns and the proportion of stocks that have a significant alpha is comparable for both models. We further investigated the significance and stability of the parameters of CAPM and Fama French three-factor model under changing economic and interest rate cycles and found that unlike the return on the market portfolio which is significant over the entire period, the significance of SMB and HML varies with both economic cycles and interest rate cycles.

Over the last four decades, several studies ${ }^{2}$ have appeared in the literature that empirically demonstrate that Sharpe's $(1963,1964)$ two-moment capital asset pricing model does not fully explain the asset pricing mechanism. In general, researchers found four shortcomings in the CAPM; namely, the model is not a good fit to the actual rates of return data because of very low coefficient of determination, the intercept term is statistically significant signaling specification error problem, the model overestimates (underestimates) the discount rates for low (high) beta stocks and beta is unstable over time. One alternative to the CAPM that has received a great deal of attention in the finance literature is the Fama French three-factor model. Fama and French (1993) developed a threefactor model that explains the average returns of investment opportunities better than any of the previous models. Whereas the central theme of the CAPM is that the return on a market portfolio is sufficient to explain asset returns, the threefactor model postulates that in addition to the loading on a market portfolio, loadings on two additional replicating portfolios, SMB, the difference between the rates of return on a portfolio of small stocks and large stocks and HML, the difference between the rates of return on a portfolio of high-book-to-market, and a portfolio of low-book-to-market stocks, are needed to explain the returns on assets. Fama and French (1996) test their three-factor model on portfolios constructed based on the market value and book value of stocks. They found that, not only is the average coefficient of determination $\left(\mathrm{R}^{2}\right)$ for the Fama French three-factor model close to one, but the constant term is insignificant as well, suggesting that the model does not suffer from misspecification error. The high $\mathrm{R}^{2}$ and the insignificance of the constant term suggest that the Fama French three-factor model does not suffer from the problem of under- or overestimation of excess returns.

${ }^{2}$ Friend and Blume (1970), Black (1972), Black, Jensen, and Scholes (1972), Miller and Scholes (1972), Blume and Friend (1973), Blume and Husick (1973), Fama and MacBeth (1973), Basu (1977), Reinganum (1981), Litzenberger and Ramaswamy (1979), Banz (1981), Gibbons (1982), Stambaugh (1982), Shanken (1987), Fama and French (1992), Kothari, Shanken, and Sloan (1995) and many others. 
The cross sectional superiority of the Fama French three-factor model over the CAPM is already academically established and started with the Fama and French (1992) claim that CAPM as a model is "dead". In a recent paper, Lawrence, Geppert and Prakash. (2007) compared the performance of the twomoment CAPM, the three-moment CAPM and the Fama French three-factor model using the Fama-French 25 portfolio data. Based on the time series and the cross sectional tests, they found that the Fama French three-factor model outperforms the other models. In this paper we do not compare CAPM and Fama and French three-factor model cross-sectionally as the question of interest here is not if the risk premiums are priced. We tested the two models in time series regressions to investigate the predictive powers of the models using individual stock returns. Using individual stock returns, we also tested the stability of the parameters of the two asset pricing models. Fama and French (1996) did not test whether the parameters of their three-factor model depend on the market conditions.

Since most of the models for portfolio selection and allocation of long-term resources (capital budgeting) use asset pricing models to compute the investors' required rate of return and/or the cost of capital, any inherent instability of the parameters ${ }^{3}$ in changing market conditions may result in an incorrect decision. Therefore, it becomes imperative to search for the model that remains largely immune to the changing market conditions. Using individual stock returns, in this paper, we test the stability of the parameters of CAPM and Fama and French three-factor model in the bear and bull market periods.

There has been a plethora of empirical studies on the effect of Federal discount rate change announcements on the asset prices (Waud (1970), Cook and Hahn (1988), Smirlock and Yawitz (1985), Jensen and Mercer (2002)). There seems to be no empirical study that has specifically examined the effect of interest changes on the parameters of asset pricing models. The Federal (Fed) monetary policies are designed to influence the overall economy and the Fed regularly use the discount rates to revive (restrict) the slowing (growing) economy by reducing (increasing) the discount rates. Though the discount rate changes are used to trigger changes in the macroeconomic variables such as overall output, employment and inflation, the most prominent and direct effect of the discount rate changes is felt in the financial markets through the changes in asset prices and their returns. If this is so, then the discount rate changes should affect the parameters of asset pricing models as well. According to Waud (1970), the stock market reacts positively to discount rate decreases and negatively to rate increases. Cook and Hahn (1988) and Smirlock and Yawitz (1985) found negative short-term market reaction to discount rate increases and vice versa. Jensen and Johnson (1995) find evidence that the long-term stock market performance is correlated with changes in the Fed discount rate. Jensen, Merces

${ }^{3}$ There is ample evidence reported in the literature indicating that the widely used twomoment capital asset pricing model (CAPM) shows significantly different results in bear and bull market periods (see, for example, Black (1972), Levy (1974) Chen (1982) Whitelaw (2000), Perez-Quiros and Timmermann (2000), and Ang and Chen (2002)). 
and Johnson (1996) claim that the monetary environment influences investor's required returns. Jensen, Johnson and Bauman (1997) provide evidence regarding the relevance of monetary conditions for asset pricing. Bernanke and Kuttner (2005) found strong and consistent response of stock markets to the unexpected changes in the Fed interest rates. These studies clearly document the influence of Fed interest rate regimes on the security prices and their returns; however none of the studies so far have studied the effect of the Fed interest rate changes on the parameters of the asset pricing models. In this paper we made an attempt to fill this gap. We tested the two asset pricing models in the chronologically delineated non-overlapping (such as bear and bull periods ${ }^{4}$ and the up and down interest rate regimes) market periods.

Success of an asset pricing model should necessarily be gauged on how well it explains the returns on single assets. Our first contribution was to show that the superior performance of the three-factor model is largely in explaining portfolio returns and not the stock returns. We performed time series analysis of the performance of the two models using both stock and portfolio return data over the 522 months, from July 1963 to December 2006. For portfolio returns we found that the average $\mathrm{R}^{2}$ of the Fama French three-factor model is a convincing $18 \%$ more than that of the CAPM. However, when these models are used on the individual stock returns, the differential average $\mathrm{R}^{2}$ falls to $5 \%$ and for those stocks where both models perform exceptional the increment is only $3 \%$. Furthermore, the proportion of stocks that have a significant alpha is comparable for both models; $7 \%$ in the Fama French three-factor model and 11\% in CAPM.

Our second contribution was an investigation of the significance and stability of the SMB and HML under changing economic and interest rate cycles. The period of our study is conducive to such an investigation since over the period there have been a number of both bull/bear markets as well as a large number of increasing/decreasing discount rate periods. We found that unlike the return on the market portfolio which is significant over the entire period, the significance of the other two factors varies with both economic cycles and interest rate cycles. In the bull and bear periods, both SMB and HML are significant in nearly all of the 25 Fama French portfolios but the significance of both SMB and HML reduces for individual stocks; SMB is significant in $60 \%$ of stocks in bull periods and $45 \%$ of stocks in bear periods whereas HML is significant in $64 \%$ of the stocks in bull periods and $70 \%$ of stocks in the bear periods. Similar to our finding for bull/bear market periods, both SMB and HML are significant in nearly all portfolios for the increasing and decreasing interest rate time periods.

${ }^{4} \mathrm{Bull}$ and bear markets are measured from the highest closing value on an index to the lowest closing value on an index, and then back again. The definition of a bull or bear market is that during a bull market, the market must rise by at least $40 \%$, preferably to a new high in the market, and the market must decline by at least $15 \%$ during a bear market. This definition fits in the "popular investment text" market definition of bull and bear market as defined by Fabozzi and Francis (1977). 
However SMB is significant in $54 \%$ of stocks in increasing interest rate periods and $53 \%$ in the decreasing interest rate periods whereas HML is significant in $69 \%$ of the stocks in the increasing interest rate time periods and is significant in $60 \%$ of the stocks in the decreasing interest rate periods. Our results indicate that the parameters for SMB and HML are significant for most of the portfolios returns but they are not significant for the individual stock returns. Also, the Fama French three-factor model shows weaker results in the bear periods and in the increasing interest rate regimes.

With respect to the stability of parameters we found the two models comparable. In the bull/bear periods, we found that the parameter for the market is different in $9 \%$ of the stocks using CAPM and $3 \%$ of the stocks using the Fama French three-factor model but the parameters for SMB and HML are different in respectively $9 \%$ and $8 \%$ of the stocks. In the Fed increasing and decreasing interest rate regimes, the parameter for the market remains nearly the same for the two models, $7 \%$ for CAPM and $8 \%$ for the three-factor model while the differences in the parameters for SMB and HML are 5\% and 3\% respectively.

The layout of the paper is as follows: in Section 2 we briefly discuss CAPM and the Fama and French three-factor model. In Section 3 we provide data and methodology. Section 4 has the empirical results. The conclusions are in Section 5.

\section{CAPM and Fama French Three-factor Model}

Under the assumptions for the CAPM, the market portfolio is efficient and there is a risk free rate available to all investors. The following pricing relationship of the security market line (SML) holds for all individual assets and their portfolios:

$$
E\left[R_{\mathrm{i}}\right]=r_{f}+\beta_{\mathrm{i}, \mathrm{M}}\left(E\left[R_{\mathrm{Mt}}\right]-r_{f}\right)
$$

where $R_{\mathrm{i}}$ denotes the return on any portfolio or asset $\mathrm{i}, R_{\mathrm{M}}$ is the return on some proxy of the market portfolio and $\beta_{\mathrm{i}, \mathrm{M}}=\operatorname{cov}\left(R_{i} R_{M}\right) / \operatorname{var}\left(R_{\mathrm{M}}\right)$. The above SML relationship allows a test of the CAPM using the following excess return market model regression equation:

$$
R_{\mathrm{it}}-r_{f}=\alpha_{\mathrm{i}}+\beta_{\mathrm{i}, \mathrm{M}}\left(R_{M t}-r_{f}\right)+\varepsilon_{\mathrm{it}}
$$

Taking expectations in the above market model we get:

$$
E\left[R_{\mathrm{i}}\right]-r_{f}=\alpha_{i}+\beta_{\mathrm{i}, \mathrm{M}}\left(E\left[R_{\mathrm{Mt}}\right]-r_{f}\right)
$$

Comparing equation 3 with the SML equation 1, we see that CAPM imposes the restriction that the intercept $\alpha_{i}$ is not significantly different from zero and the coefficient on the excess market return (the beta coefficient) is statistically significant. 
In the late 70 s and 80 s a number of anomalies concerning certain firm specific characteristics that seem to have explanatory power for the cross-section of returns beyond the market beta of the CAPM were reported. For example, Basu (1977) provides evidence that when common stocks are sorted on earnings-price ratios, future returns on high E/P stocks are higher than predicted by the CAPM and Banz (1981) document a size effect where low market capitalization firms have higher sample mean returns than would be expected if the market portfolio was mean-variance efficient. Other researchers document a leverage effect and a role for the ratio of the book value of a firm's equity to its market value, (BE/ ME). ${ }^{5}$ Fama and French (1992) investigate the joint role of all these variables by including all of them in their Fama-MacBeth style cross-sectional regression using portfolios formed first on size and then on betas. Using a sample of monthly returns for non-financial firms on NYSE, AMEX and Nasdaq from 1962-1989, they find that beta does not explain the cross-section of average stock returns, there is a negative relation between size and return, book-to-market equity is significantly positively related to average returns and the combination of size and book-to-market equity seem to absorb the roles of leverage and E/P ratio. They conclude that the two dimensions of risk which are priced are proxied by size and the ratio of book value of equity to market value of equity. Fama and French (1996) also report similar findings using the time-series regression approach applied to portfolios of stocks sorted on price ratios. The evidence provided by Fama and French (1992) started the claims that CAPM as a model is "dead". This has however been countered by other researches who consider Fama and French results to be spurious and the result of data mining, (Kothari et al. 1995).

In using time series regressions to test if the factors in the three-factor model are sufficient to explain asset returns, the following model is used.

$$
R_{i t}-R_{f t}=\alpha_{\mathrm{i}}+\beta_{\mathrm{i}}\left(R_{\mathrm{mt}}-R_{f t}\right)+s_{i} \mathrm{SMB}_{\mathrm{t}}+h_{i} \mathrm{HML}_{\mathrm{t}}+\varepsilon_{\mathrm{it}}
$$

I If the three-factor model holds, then all three-factor coefficients are significantly different from zero and the intercept is not significantly different from zero. The three-factor model is now widely used in empirical research that requires a model of expected returns. It has been used in event studies to test for abnormal performance (Loughran and Ritter (1995); Mitchell and Stafford (2000) as well as models that study mutual fund performance (Carhart, 1997). However, todate there is no theory underlying this model.

\section{Data and Methodology}

\section{A. Data}

The data for this study consisted of all firms with monthly return data on CRISP from July, 1963 to December 2006. Monthly value-weighted market return,

${ }^{5}$ Bhandari (1988) found that high debt-equity ratios are associated with returns that are too high relative to their market betas and Rosenberg, Reid and Lanstein (1985) documented that stocks with high book-to-market equity ratios have higher average returns than predicted by their betas. 
return on the benchmark portfolios, HML, SMB and the monthly risk-free rate of return for the sample period are obtained from Kenneth French's website. We also obtained monthly value-weighted return on the 25 Fama-French portfolios which are the intersection of 5-size sort and 5-BE/ME sort from KennethFrench's website. Table 1 provides summary statistics of the data. We included only those stocks that have been continuously traded over the sample period, a total of 245 stocks. Over the sample period the mean monthly excess return on the market is $0.476 \%$ which is similar to the value of $0.47 \%$ that was reported by Fama and French (2006) for their July 1963 to December 2004 period.

\section{B. Individual Asset Returns}

We performed time series analysis on each of the individual stocks and each of the 25 Fama French portfolios using the following two models:

$$
\begin{aligned}
& C A M P: R_{i t}-R_{f t}=a_{\mathrm{i}}+\beta_{\mathrm{i}}\left(R_{\mathrm{mt}}-R_{f \mathrm{t}}\right)+\varepsilon_{\mathrm{t}} \\
& F F 3 F: R_{i t}-R_{f \mathrm{t}}=a_{\mathrm{i}}+\beta_{\mathrm{i}}\left(R_{\mathrm{mt}}-R_{f \mathrm{t}}\right)+s_{\mathrm{i}} S M B+h_{i} \mathrm{HML}+\varepsilon_{\mathrm{t}}
\end{aligned}
$$

In the above models we tested for the significance of the coefficient of determination of CAPM and FF3F. In addition, we also test if the significance of the intercept is close to zero and , $\beta_{\mathrm{i}} s_{i}$ and $h_{i}$ are significantly different from zero.

\section{Stability Tests over Different Market Conditions}

We investigate the stability of the parameters in CAPM and the Fama French three-factor model over bear/bull economic cycles and the Fed interest rate cycles. Similar to the models used by Fabozzi and Francis (1977) we extend the CAPM and the three-factor model to include dummy variables for Bull/Bear market conditions and Increasing/Decreasing interest rate periods.

The extended models that we use to test the stability of the parameters over bull/bear market conditions are:

$$
\begin{aligned}
\text { CAPMBB : } R_{i t}-R_{f t} & =a_{i}^{B U L L} B B_{t}+a_{i}^{B E A R}\left(1-B B_{t}\right) \\
& +\beta_{i}^{B U L L} B B_{t}\left(R_{m t}-R_{f t}\right)+\beta_{i}^{B E A R}\left(1-B B_{t}\right)\left(R_{m t}-R_{f t}\right)+\varepsilon_{t} \\
\text { FF3FBB : } R_{i t}-R_{f t} & =\alpha_{i}^{B U L L} B B_{t}+a_{i}^{B E A R}\left(1-B B_{t}\right) \\
& +\beta_{i}^{B U L L} B B_{t}\left(R_{m t}-R_{f t}\right)+\beta_{i}^{B E A R}\left(1-B B_{t}\right)\left(R_{m t}-R_{f t}\right) \\
& +s_{i}^{B U L L} B B_{t} S M B_{t}+s_{i}^{B E A R}\left(1-B B_{t}\right) S M B_{t} \\
& +h_{i}^{B U L L} B B_{t} H M_{t}+h_{i}^{B E A R}\left(1-B B_{t}\right) H M L_{t}+\varepsilon_{t}
\end{aligned}
$$




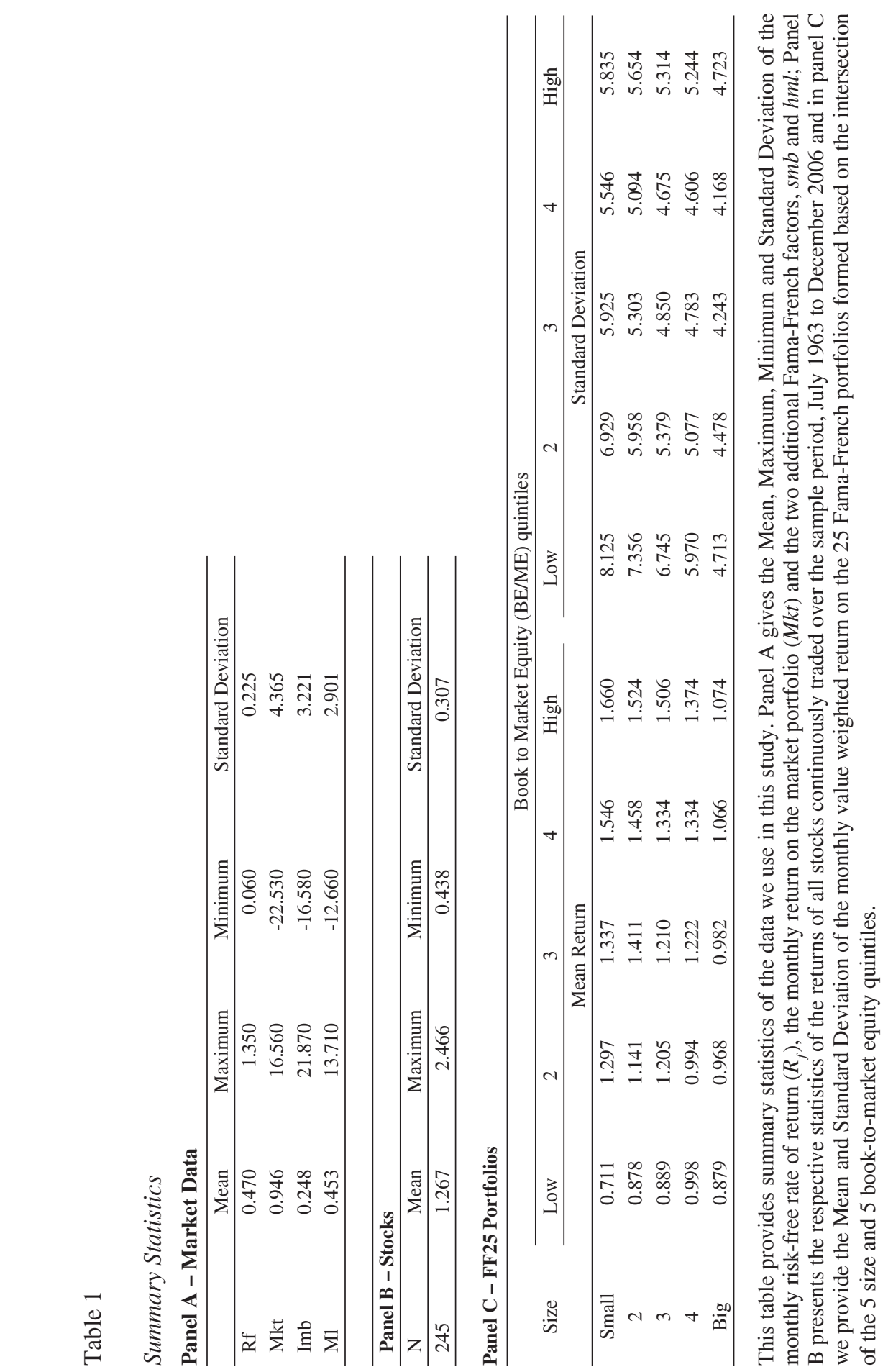


BB is a dummy variable which has a value of " 1 " for months that are part of bull market periods and zero otherwise. We used. similar models to test the stability of the parameters over different discount rate periods, by including a dummy variable, DR which takes a value of " 1 " for months when the discount rate is increasing and zero otherwise:

$$
\begin{aligned}
\text { CAPMDR: } R_{i t}-R_{f t} & =a_{i}^{I N C R} D R_{t}+a_{i}^{D E C R}\left(1-D R_{t}\right) \\
& +\beta_{i}^{I N C R} D R_{t}\left(R_{m t}-R_{f t}\right)+\beta_{i}^{D E C R}\left(1-D R_{t}\right)\left(R_{m t}-R_{f t}\right)+\varepsilon_{t}
\end{aligned}
$$

$$
\text { FF3FDR: } \begin{aligned}
R_{i t}-R_{f t} & =\alpha_{i}^{I N C R} D R_{t}+a_{i}^{D E C R}\left(1-D R_{t}\right) \\
& +\beta_{i}^{I N C R} D R_{t}\left(R_{m t}-R_{f t}\right)+\beta_{i}^{D E C R}\left(1-D R_{t}\right)\left(R_{m t}-R_{f t}\right) \\
& +s_{i}^{I N C R} D R_{t} S M B_{t}+s_{i}^{D E C R}\left(1-D R_{t}\right) S M B_{t} \\
& +h_{i}^{I N C R} D R_{t} H M L_{t}+h_{i}^{D E C R}\left(1-D R_{t}\right) H M L_{t}+\varepsilon_{t}
\end{aligned}
$$

We first tested the significance of the market factor in explaining individual stock returns over different market conditions using models CAPMBB and CAPMDR. Then, using stock data, we investigate the stability of the additional factors in the Fama French three- factor model by estimating models FF3FBB and FF3FDR. Specifically, our null hypotheses are:

$$
\begin{aligned}
& h_{01}: \beta_{i}^{B U L L}=\beta_{i}^{B E A R} \\
& h_{02}: s_{i}^{B U L L}=s_{i}^{B E A R} \\
& h_{03}: h_{i}^{B U L L}=h_{i}^{B E A R} \\
& h_{04}: \beta_{i}^{I N C R}=\beta_{i}^{D E C R} \\
& h_{05}: s_{i}^{I N C R}=s_{i}^{D E C R} \\
& h_{06}: h_{i}^{I N C R}=h_{i}^{D E C R}
\end{aligned}
$$

\section{Empirical Results}

\section{A. Individual Asset Returns vs. Portfolio Returns}

Panel A of Table 2 provides regression results of the CAPM and the Fama French three-factor model for the individual stocks in our sample and Panel B provides similar results for the Fama French 25 portfolios. For portfolio returns, our results are similar to those of Fama and French $(1993,1995,1996)$. For the CAPM the $\mathrm{R}^{2}$ ranges from a low of $58 \%$ to a high of $87 \%$ with an average of $73 \%$; while for the Fama French three-factor model, the lowest $\mathrm{R}^{2}$ is $79 \%$, the highest is $95 \%$ and the average $\mathrm{R}^{2}$ is a convincing $91 \%$. In addition, whereas the intercept is significant in 15 of the portfolios when CAPM is used, this number is reduced to 8 using the Fama French three-factor model. 


\section{Table 2}

Comparison of Time Series Regressions of Stocks vs. Fama French 25 Sizel BEME Portfolios

Number and Proportion of Stocks (Portfolios) with Significant Parameters

\begin{tabular}{|c|c|c|c|c|c|c|c|}
\hline Model & Ave. $\mathrm{R}^{2}$ & $\operatorname{Max}^{2}$ & $\operatorname{Min} \mathrm{R}^{2}$ & $\alpha$ & $\beta$ & $\mathrm{s}$ & $\mathrm{h}$ \\
\hline \multicolumn{8}{|c|}{ Panel A: Stocks } \\
\hline \multirow[t]{2}{*}{ CAPM } & $22 \%$ & $60 \%$ & $3 \%$ & 26 & 245 & & \\
\hline & & & & $11 \%$ & $100 \%$ & & \\
\hline \multirow{2}{*}{ FF3F } & $27 \%$ & $63 \%$ & $4 \%$ & 17 & 245 & 164 & 191 \\
\hline & & & & $7 \%$ & $100 \%$ & $67 \%$ & $78 \%$ \\
\hline \multicolumn{8}{|c|}{ Panel B: 25 Size/BEME Portfolios } \\
\hline \multirow[t]{2}{*}{ CAPM } & $73 \%$ & $87 \%$ & $58 \%$ & 15 & 25 & & \\
\hline & & & & $60 \%$ & $100 \%$ & & \\
\hline \multirow[t]{2}{*}{ FF3F } & $91 \%$ & $95 \%$ & $79 \%$ & 8 & 25 & 25 & 25 \\
\hline & & & & $32 \%$ & $100 \%$ & $100 \%$ & $100 \%$ \\
\hline
\end{tabular}

In this table we report the regression results for the following two models:

$$
\begin{gathered}
C A P M: R_{i t}-R_{f t}=a_{i}+\beta_{i}\left(R_{m t}-R_{f t}\right)+\varepsilon_{t} \\
F F 3 F: R_{i t}-R_{f t}=a_{i}+\beta_{i}\left(R_{m t}-R_{f t}\right)+s_{i} S M B_{t}+h_{i} H M L_{t}+\varepsilon_{t}
\end{gathered}
$$

In Panel A, we provide the results for the time series regression with the dependent variable being the monthly stock return on each of the 245 stocks continuously traded over the sample period of July 1963 to December 2006. In Panel B we present the regression results for the 25 Size/BEME portfolios.

The results for the individual stocks reported in Panel A are less convincing. Here the range of $\mathrm{R}^{2}$ is similar for the two models, $3 \%$ to $60 \%$ for the CAPM and $4 \%$ to $63 \%$ for the three-factor model. Also, unlike the results for the Fama French 25 portfolios in Panel B where we get an $18 \%$ improvement in average $\mathrm{R}^{2}$ using the Fama French three-factor model versus the CAPM model, with individual stocks, the difference in average $\mathrm{R}^{2}$ is only $5 \%$. In addition, for CAPM, the intercept is significant in $11 \%$ of the stocks compared to $7 \%$ for the three-factor model. Whereas, SMB and HML are significant in explaining 
the returns of all 25 portfolios, they are significant only in 67\% (SMB) and $78 \%$ (HML) of the stocks. Together these results provided evidence that the improvements in the Fama French three-factor model over the CAPM is in explaining portfolio returns than individual stock returns.

\section{B. Bull/Bear Markets}

In Appendix 1, we provided the start and end date of the bull/bear periods and a summary of the total number of months for each. In Table 3 we present the results of the regression models when the CAPM and the Fama French threefactor models are extended to include dummies for the Bull/Bear months. Comparison of Panels A and B shows that only the market factor is consistently significant in explaining both stock and portfolio returns during the bull and bear market periods. In the bear period, both SMB and HML are significant in all the portfolios but in bull periods, SMB is significant in $96 \%$ of portfolios whereas HML is significant in $88 \%$ of the portfolios. The significance of both SMB and HML reduces for individual stocks; SMB is significant in $60 \%$ of stocks in the bull period and $45 \%$ of stocks in the bear period whereas HML is significant in $64 \%$ of stocks in the bull period and $70 \%$ of stocks in the bear period. The results indicated that parameters for SMB and HML are significant for most of the portfolio returns but they are not significant for nearly half of the individual stock returns. The three-factor model shows weaker results in the bear periods where the parameter for SMB is insignificant for $55 \%$ of the stocks.

\section{Increasing/Decreasing Interest Rates}

In Appendix 2, we provided the start and end date of the increasing and decreasing interest rate periods and a summary of the total number of months for each. Over the sample period, the number of months during which the interest rates was increasing is approximately equal to the number of months when interest rate was decreasing (266 vs. 256). 


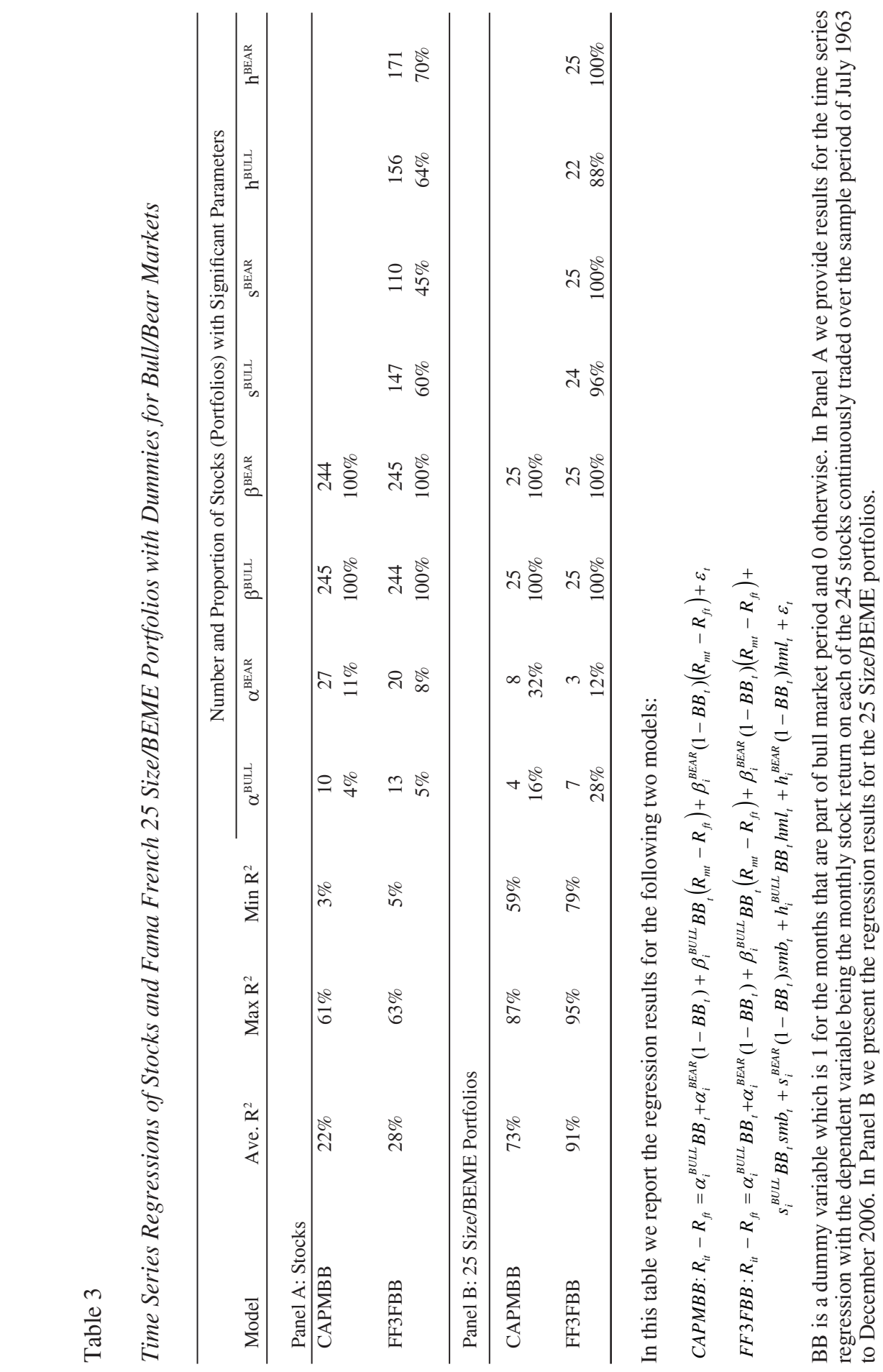




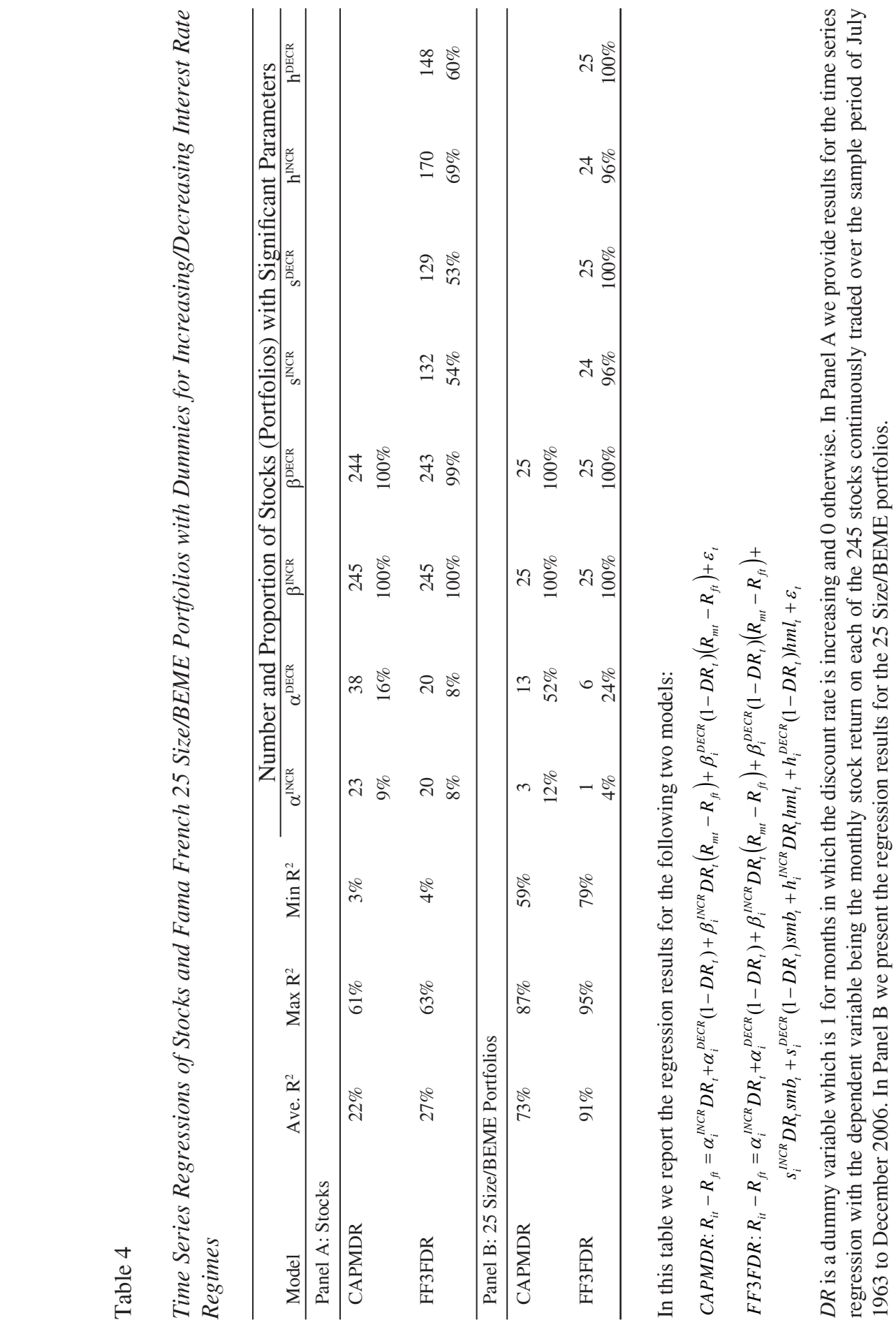


Table 5

Test of Equivalence of Slopes

\begin{tabular}{|c|c|c|c|c|c|c|}
\hline \multicolumn{7}{|c|}{ Number and Proportion of Stocks (Portfolios) with Different Coefficients } \\
\hline Model & $\beta^{\text {BULL }} / \beta^{\text {BEAR }}$ & $\mathrm{s}^{\mathrm{BULL}} / \mathrm{s}^{\mathrm{BEAR}}$ & $\mathrm{h}^{\mathrm{BULL}} / \mathrm{h}^{\mathrm{BEAR}}$ & $\beta^{\mathrm{INCR}} / \beta^{\mathrm{DECR}}$ & $\mathrm{s}^{\mathrm{INCR} / \mathrm{s}^{\mathrm{DECR}}}$ & $\mathrm{h}^{\mathrm{INCR}} / \mathrm{h}^{\mathrm{DECR}}$ \\
\hline \multicolumn{7}{|c|}{ Panel A: Stocks } \\
\hline \multirow[t]{2}{*}{ CAPMBB } & 23 & & & & & \\
\hline & $9 \%$ & & & & & \\
\hline \multirow[t]{2}{*}{ FF3FBB } & 7 & 22 & 19 & & & \\
\hline & $3 \%$ & $9 \%$ & $8 \%$ & & & \\
\hline \multirow[t]{2}{*}{ CAPMDR } & & & & 18 & & \\
\hline & & & & $7 \%$ & & \\
\hline \multirow[t]{2}{*}{ FF3FDR } & & & & 19 & & 8 \\
\hline & & & & $8 \%$ & & $3 \%$ \\
\hline \multicolumn{7}{|c|}{ Panel B: 25 Size/BEME Portfolios } \\
\hline \multirow[t]{2}{*}{ CAPMBB } & 10 & & & & & \\
\hline & $40 \%$ & & & & & \\
\hline \multirow[t]{2}{*}{ FF3FBB } & 4 & 0 & 12 & & & \\
\hline & $16 \%$ & $0 \%$ & $48 \%$ & & & \\
\hline \multirow[t]{2}{*}{ CAPMDR } & & & & 0 & & \\
\hline & & & & $0 \%$ & & \\
\hline \multirow[t]{2}{*}{ FF3FDR } & & & & 2 & 7 & 7 \\
\hline & & & & $8 \%$ & $28 \%$ & $28 \%$ \\
\hline
\end{tabular}

In this table we report results for the tests of equivalence of slopes for each of the models previously reported and described in the texts with dummies included for bull/bear market periods and increasing/decreasing interest rate periods respectively. In Panel A we present the results of the test of slope coefficients for the individual stocks and in Panel B we report the results for the 25 size/BEME portfolios. The results are based on F-statistics significant at the $1 \%$ level.

In Table 4, we present the results of the regression models when the CAPM and the Fama French three-factor models are extended to include dummies for the Increasing/Decreasing Interest rate periods. Comparison of Panels A and B shows that only the market factor is consistently significant in explaining both stock and portfolio returns during the different interest rate periods. Similar to our finding for bull/bear market periods, both SMB and HML are significant in almost all portfolios for the increasing and decreasing interest rate time periods. However, for individual stocks, the significance of both SMB and HML reduces significantly. SMB is significant in 54\% of stocks in increasing interest rate periods and $53 \%$ in the decreasing interest rate periods. HML is significant in 
$69 \%$ of the stocks in the increasing interest rate time periods and is significant in $60 \%$ of the stocks in the decreasing interest rate periods.

In Table 5, we provide the results for the F-tests of equivalence of the slope coefficients for each of the two models in the bear/bull and the Fed interest rate increasing/decreasing time periods. For CAPM, beta is different in $9 \%$ of the stocks in the bear/bull periods and $18 \%$ of the stocks in the increasing/ decreasing interest rate periods. For the Fama French three-factor model, beta is different in $3 \%$ of stocks in the bear/bull periods and $8 \%$ of stocks in the increasing/decreasing interest rate periods.

The parameters for SMB and HML are different in respectively $9 \%$ and $8 \%$ stocks in the bear/ bull time periods and respectively $5 \%$ and $3 \%$ stocks in the increasing/decreasing interest rate periods. The differences in the parameters are more prominent in the portfolio returns where for the bear/bull market period, beta values are different for $40 \%$ of the portfolios for CAPM and $16 \%$ of the portfolios for the three-factor model. For the increasing/decreasing interest rate periods there is no difference in the beta values for CAPM but the beta values are different for $8 \%$ of portfolios for the three-factor model. The parameter for SMB is not different for any of the 25 portfolios in the bear/bull periods. It is different for $28 \%$ portfolios in the increasing/decreasing interest rate periods. The parameter for HML is different in $48 \%$ of the portfolios in the bear/bull periods and $28 \%$ of the portfolios in the increasing/decreasing interest rate periods. Panels $\mathrm{A}$ and $\mathrm{B}$ shows that the market factor is generally more stable than SMB and HML in explaining both stocks and portfolio returns over different market conditions.

\section{Conclusions}

In practice, asset pricing models are used to compute the expected returns of individual assets. These returns are then used in the computation of fundamental price of stock by investors and the net present value of projects by corporate managers. Even though asset pricing models are used for the individual assets they are invariably tested using portfolio return data to avoid the problem of errors in variables. Though CAPM is inarguably the most used model by practitioners, it performs poorly when tested against the Fama French three-factor model using portfolio return data. In this paper we tested the performance of CAPM and the Fama French three-factor model using individual stock return data and find that the Fama French three-factor model performs marginally better than the CAPM. We also testwd the stability of parameters of the two models in the economic conditions (bear and bull periods and the Federal increasing and decreasing interest rate regimes) and found the two models comparable. 
Author information: Submitting author, Edward R. Lawrence, Assistant Professor of Finance, College of Business Administration, Florida International University, Miami, Fl 33199. Phone: (305)348-0082. Email: elawrence@flu. edu Ann Marie Hibbert is an Assistant Professor of Finance, West Virginia University, WV 26506-6025, Tel (304)293-2447. Email: annmarie.hibbert@ mail.wvu.edu.

Appendix 1

Bull/Bear Periods from July 1963 to December 2006

\begin{tabular}{|c|c|c|c|c|}
\hline \multicolumn{3}{|l|}{ Time Period } & \multicolumn{2}{|c|}{ Bull/Bear Months } \\
\hline July 1, 1963 & to & February 9, 1966 & Bull & 31 \\
\hline February 9, 1966 & to & October 7, 1966 & Bear & 8 \\
\hline October 7, 1966 & to & $\begin{array}{l}\text { November 29, } \\
1968\end{array}$ & Bull & 26 \\
\hline November 29, 1968 & to & May 26, 1970 & Bear & 18 \\
\hline May 26, 1970 & to & January 11, 1973 & Bull & 32 \\
\hline January 11, 1973 & to & December 6, 1974 & Bear & 23 \\
\hline December 6, 1974 & to & $\begin{array}{l}\text { September 21, } \\
1976\end{array}$ & Bull & 21 \\
\hline September 21, 1976 & to & February 28, 1978 & Bear & 17 \\
\hline February 28, 1978 & to & April 27, 1981 & Bull & 38 \\
\hline April 27, 1981 & to & August 12, 1982 & Bear & 15 \\
\hline August 12, 1982 & to & August 25, 1987 & Bull & 61 \\
\hline August 25, 1987 & to & October 19, 1987 & Bear & 2 \\
\hline October 19,1987 & to & July 16,1990 & Bull & 33 \\
\hline July 16, 1990 & to & October 11,1990 & Bear & 3 \\
\hline October 11,1990 & to & July 17, 1998 & Bull & 93 \\
\hline July 17,1998 & to & October 5, 1998 & Bear & 3 \\
\hline October 5, 1998 & to & January 14, 2000 & Bull & 15 \\
\hline January 14, 2000 & to & October 9, 2002 & Bear & 33 \\
\hline October 9, 2002 & to & December 31, 2006 & Bull & 51 \\
\hline
\end{tabular}




\section{Appendix 2}

Periods of Increasing/Decreasing Interest Rates from July 1963 to December 2006

\begin{tabular}{|c|c|c|c|c|}
\hline \multicolumn{3}{|c|}{ Time Period } & \multirow{2}{*}{$\begin{array}{c}\text { Series } \\
\text { Increasing }\end{array}$} & \multirow{2}{*}{$\begin{array}{c}\begin{array}{c}\text { Number } \\
\text { of Months }\end{array} \\
47\end{array}$} \\
\hline July, 1963 & to & March, 1967 & & \\
\hline April, 1967 & to & October, 1967 & Decreasing & 7 \\
\hline November, 1967 & to & July, 1968 & Increasing & 9 \\
\hline August, 1968 & to & November, 1968 & Decreasing & 4 \\
\hline December, 1968 & to & October, 1970 & Increasing & 23 \\
\hline November, 1970 & to & June, 1971 & Decreasing & 8 \\
\hline July, 1971 & to & October, 1971 & Increasing & 4 \\
\hline November, 1971 & to & December, 1972 & Decreasing & 14 \\
\hline January, 1973 & to & November, 1974 & Increasing & 23 \\
\hline December, 1974 & to & July, 1977 & Decreasing & 32 \\
\hline August, 1977 & to & April, 1980 & Increasing & 33 \\
\hline May, 1980 & to & August, 1980 & Decreasing & 4 \\
\hline September, 1980 & to & October, 1981 & Increasing & 14 \\
\hline November, 1981 & to & March, 1984 & Decreasing & 29 \\
\hline April, 1984 & to & October, 1984 & Increasing & 7 \\
\hline November, 1984 & to & August, 1987 & Decreasing & 34 \\
\hline September, 1987 & to & November, 1990 & Increasing & 39 \\
\hline December, 1990 & to & April, 1994 & Decreasing & 41 \\
\hline May, 1994 & to & December, 1995 & Increasing & 20 \\
\hline January, 1996 & to & July, 1999 & Decreasing & 43 \\
\hline August, 1999 & to & December, 2000 & Increasing & 17 \\
\hline January, 2001 & to & May, 2004 & Decreasing & 41 \\
\hline \multirow[t]{3}{*}{ June, 2004} & to & December, 2006 & Increasing & 31 \\
\hline & & & $\begin{array}{l}\text { Total } \\
\text { Increasing }\end{array}$ & 266 \\
\hline & & & $\begin{array}{l}\text { Total } \\
\text { Decreasing }\end{array}$ & 256 \\
\hline
\end{tabular}




\section{References}

Ang, A., and Chen, J., (2002). Asymmetric correlations of equity portfolios. Journal of Financial Economics, 63, 443-494.

Banz, R.W., (1981). The relationship between return and market value of common stocks. Journal of Financial Economics, 9, 3-18.

Basu, S., (1977). Investment performance of common stocks in relation to their price-earnings ratios: A test of the efficient market hypothesis. The Journal of Finance, 32, 663-682.

Bernanke, B., and Kuttner, K.N., (2005). What explains the stock market's reaction to Federal Reserve policy? The Journal of Finance, 60, 12211257.

- Bhandari, L.C., (1988). Debt/Equity ratio and expected common stock returns: empirical evidence. The Journal of Finance, 43, 507-528.

Black, F., (1972). Capital market equilibrium with restricted borrowing. Journal of Business, 45, 444-455.

Black, F., Jensen, M.C., and Scholes, M., (1972). The capital asset pricing model: Some empirical tests. Praeger, New York.

Blume, M.E., (1970). Portfolio theory: A step toward its practical application. Journal of Business, 43, 152-173.

Blume, M.E., and Friend, I., (1973). A new look at the capital asset pricing model. Journal of Finance, 28, 19-33.

Blume, M.E., and Husick, F., (1973). Price, beta and exchange listing. Journal of Finance 28, 283-299.

Carhart, M.M., (1997). On persistence in mutual fund performance. The Journal of Finance, 52, 57-82.

Chen, S.N., (1982). An examination of risk return relationship in bull and bear markets using time varying betas. Journal of Financial and Quantitative Analysis, 17, 265-286.

Cook, T., and Hahn, T., (1988). The information content of discount rate announcements and their effect on market interest rates. Journal of Money, Credit and Banking, 20, 167-180.

Fabozzi, F.J., and Francis, J.C., (1977). Stability tests for alphas and betas over bull and bear market conditions. The Journal of Finance, 32, 1093-1099.

Fama, E.F., and French, K.R., (1992). The cross-section of expected stock returns. The Journal of Finance, 47, 427-465.

Fama, E.F., and French, K.R., (1993). Common risk factors in the returns on stocks and bonds. Journal of Financial Economics, 33, 3-56.

Fama, E.F., and French, K.R., (1995). Size and book-to-market factors in earnings and returns. The Journal of Finance, 50, 131-155.

Fama, E.F., and French, K.R., (1996). Multifactor explanations of asset pricing anomalies. The Journal of Finance, 51, 55-84.

Fama, E.F., and French, K.R., (2006). The value premium and the CAPM. The Journal of Finance, 61, 2163-2185. 
Fama, E.F., and MacBeth, J.D., (1973). Risk, return, and equilibrium: empirical tests. The Journal of Political Economy, 81, 607-636.

Friend, I., and Blume, M., (1970). Measurement of portfolio performance under uncertainty. American Economic Review, 60, 561-575.

Gibbons, M.R., (1982). Multivariate tests of financial models. Journal of Financial Economics, 10, 3-27.

Graham, J.R., and Harvey, C.R., (2001). The theory and practice of corporate finance: evidence from the field. Journal of Financial Economics, 60, 187-243.

Jensen, G.R., and Johnson, R.R., (1995). Discount rate changes and security returns in the US, 1962-1991. Journal of Banking and Finance, 19, 79-95.

Jensen, G.R., Johnson, R.R., and Bauman, W.S., (1997). Federal Reserve monetary policy and industry stock returns. Journal of Business Finance \& Accounting, 24, 629-644.

Jensen, G.R., and Mercer, J.M., (2002). Monetary policy and the cross-section of expected stock returns. The Journal of Financial Research, 25, 125-139.

Jensen, G.R., Mercer, J.M., and Johnson, R.R., (1996). Business conditions, monetary policy, and expected security returns. Journal of Financial Economics, 40, 213-237.

Kothari, S.P., Shanken, J., and Sloan, R.G., (1995). Another look at the crosssection of expected stock returns. The Journal of Finance, 50, 185-224.

Lawrence, E.R., Geppert, J., and Prakash, A.J., (2007). Asset pricing models: A comparison. Applied Financial Economics, 17, 933-940.

Levy, R.A., (1974). Beta coefficients as predictors of return. Financial Analysts Journal, 30, 61-9.

Litzenberger, R.H., and Ramaswamy, K., (1979). The effects of dividends on common stock prices: Theory and empirical evidence. Journal of Financial Economics, 7, 163-195.

Loughran, T., and Ritter, J.R., (1995). The new issues puzzle. The Journal of Finance, 50, 23-51.

Miller, M.H., and Scholes, M., (1972). Rates of return in relation to risk: A reexamination of some recent findings. In Michael C. Jensen (Ed.), Studies in the theory of capital market (pp. 47-78). New York: Praeger.

Mitchell, M.L., and Stafford, E., (2000). Managerial decisions and long-term stock price performance. Journal of Business, 73, 287.

Perez-Quiros, G., and Timmermann, A., (2000). Firm size and cyclical variations in stock returns. The Journal of Finance, 55, 1229-1262.

Reinganum, M.R., (1981). A new empirical perspective on the CAPM. Journal of Financial and Quantitative Analysis, 16, 439-462.

Rosenberg, B., Reid, K., and Lanstein, R., (1985). Persuasive evidence of market inefficiency. Journal of Portfolio Management, 11, 9-17.

Shanken, J., (1987). Multivariate proxies and asset pricing relations: Living with the Roll critique. Journal of Financial Economics, 18, 91-110. 
Sharpe, W.F., (1963). A simplified model for portfolio analysis. Management Science (pre-1986) , 9, 277-293.

Sharpe, W.F., (1964). Capital asset prices: A theory of market equilibrium under conditions of risk. The Journal of Finance, 19, 425-442.

Smirlock, M., and Yawitz, J., (1985). Asset returns, discount rate changes, and market efficiency. The Journal of Finance, 40, 1141-1158.

Stambaugh, R.F., (1982). On the exclusion of assets from tests of the twoparameter model: A sensitivity analysis. Journal of Financial Economics, 10, 237-268.

Waud, R.N., (1970). Public interpretation of Federal Reserve discount rate changes: Evidence on the 'Announcement Effect'. Econometrica, 38, 231-250.

-Whitelaw, R.F., (2000). Stock market risk and return: An equilibrium approach. The Review of Financial Studies, 13, 521-547. 